\title{
Contact Dermatitis Due to Spandex
}

\author{
E. \\ van Dijk
}

Department of Dermatology, Academic Hospital of the Free University, Amsterdam

Three women with contact dermatitis due to spandex in their brassieres are reported. Two of these patients had a previous history of rubber sensitivity. Patch tests were performed with a number of rubber accelerators

antioxydants

wonderlastic (Playtex)

lycra and rubber. All three patients showed positive patch tests with wonderlastic zinc diethyl dithiocarbamate and N-phenyl-N'-isopropyl-para-phenylenediamine. Patch tests with 2-mercaptobenzothiazole were only positive in the two patients sensitive to rubber.

(To be published in Acta derm.-vener.). 